\title{
Analysis of Rural-Based Pre-Service Teachers Spatial- Visualisation Skills in Problem Solving in Vector Calculus Using MATLAB
}

\author{
https://doi.org/10.3991/ijet.v16i10.19269 \\ Amevor Godfred \\ University of Zululand, Richards Bay, South Africa \\ Anass Bayaga $(\bowtie)$ \\ Nelson Mandela University, Port Elizabeth, South Africa \\ anass.bayaga@mandela.ac.za \\ Micheal J. Bosse \\ Appalachian State University, Boone, USA
}

\begin{abstract}
In science, technology, engineering, and mathematics (STEM) for instance, interdisciplinary studies have noted positive correlation between spatial-visualization (SV skills) and mathematical problem solving. Most of these studies sharing a link between SV skills and problem solving were contextualized in urban settings and only a few in rural settings. However, the current investigation examines how rural-based pre-service teachers apply their SV skills in problem-solving in a South African university, in the context of vector calculus. One hundred rural-based pre-service teachers in a second-year vector calculus class at University of Zululand (UNIZULU) were randomly selected into control and experimental groups. MATLAB was used as a dynamic visual tool to analyse how research participants applied their SV skills. A mixed method approach was employed in data collection (quantitative and qualitative). Our findings revealed that the rural-based pre-service teachers' SV skills correlate with their problem-solving skills in vector calculus.
\end{abstract}

Keywords - Cognitive skills, problem-solving, Spatial visualisation, vector calculus, visual-analyser

\section{Introduction}

Majority of educators and learners have limited to no formal training in e-learning of mathematical content and pedagogy, or mathematical epistemology. Consequently, there is a need for research in mathematical learning, particularly to address the needs of learner-teacher centeredness. In response to such need, the current research presents the analysis of how rural-based pre-service teachers apply their spatial visualisation (SV) skills in problem-solving in vector calculus. There is number of disconnected previous studies $[61,81]$ (difficulties with integral calculus are related to poor prior 
knowledge of trigonometric identities); a textbook on vector calculus [19, 45], regarding difficulties in solving physics problems using multiple representations [37, $34,29,67]$. In addition, previous analyses of how rural-based students generally apply spatial-visualisation skills in problem solving suggests various factors. For instance, evidence supports the claim that poor family social economic status (SES) hinders cognitive development [56]. Hence, students from lower SES backgrounds have less SV skills and weaknesses regarding problem solving. Others state that SV skills and problem solving of 6-8-year-old students can be enhanced through spatial activities (e.g., arrangement of cube boxes) [8].

One may immediately ask how this study adds to and differentiates itself from the extant literature. Thus, questioning learning and technology nexus: First, we extend the existing literature by considering student learning through the dynamic computer environment of MATLAB. Second, we consider learning through MATLAB in the context of mathematics, not physics as is commonly the case. Third, we investigate the topic of collegiate vector calculus. While mathematical learning in respect to university students is growing, it remains far eclipsed by research involving younger students. Additionally, only a handful of studies seem to consider student learning above college algebra or trigonometry. Fourth, we look specifically at a population of university preservice teachers, who may be teaching some calculus concepts in their future employment and not at math, science, or physics majors who may have very different uses for this type of technological environment in their future careers. Fifth, although most research regarding student learning through dynamic technology tools is performed in more affluent settings, we consider university students in a high poverty, rural region of South Africa - students with limited exposure to instructional technology before entering college and limited experience with math-specific technology in college. Altogether, these dimensions situate this study in the literature and their total demonstrates a need for additional research.

Jointly, in response to the focus on the advantages of new technologies may contribute to the learning process and how this is proofed, the current study thus reflects on use of MATLAB in augmenting and enhancing student learning. It thus examines how the MATLAB changes the method of teaching and learning.

\section{$2 \quad$ Literature Review}

Based on the aforementioned studies and theoretical perspective on spatial visualisation [63, 65], the authors of the current study examine a range of conceptual underpinnings for; a) SV skills and problem-solving, b) the fact that spatial ability supports mathematical aptitude, c) visual interactions and mental rotations, and d) the role of SV skills in problem-solving in vector calculus. This study: examines a less frequently researched population (college students); using a technology tool (MATLAB); in a less common manner (mathematics rather than physics); in an infrequently investigated topic (vector calculus); pertaining to preservice teachers in a high-poverty, rural region of South Africa who may be teaching some of these concepts in the future more so than practitioners of vector calculus; through the lens of SV skills. Very lim- 
ited extant research specifically applies simultaneously to all these dimensions. Thus, connections - some tenuous - a must be made with research regarding other populations and topics, and skills in order to better understand this nexus of these dimensions. This review of the literature attempts to make some of these connections and weave a cogent argument.

\subsection{Spatial visualisation, problem-solving and rural influence}

Recently, various researchers $[6,21,28,35,51,66]$ associated spatial visualisation (SV) as a reflection or measurement of intelligence and problem-solving. It has been asserted that "spatial visualization is the ability to manipulate an object in an imaginary 3-D space and create a new representation of the object from a new viewpoint" [52]. Others [10, 42,] found SV to be a powerful tool for problem-solving.

There seems to also be some disconnected and potentially contradictory evidence that can yet be woven together to suggest that illustrations facilitate a better understanding of problem solutions $[11,25,38]$. In the context of integral calculus, researchers investigated the types of cues - often in the form of illustrations - students employed to recognize the need for integration and the difficulties students encountered with setting up and evaluating integrals [38, 37]. Researchers [38, 37, 44] have defined problem-solving in vector calculus as a cognitively challenging task that involves a mathematical problem/situation - often visualized through an illustration for which a solution is not readily known.

Vector calculus is, by nature, a description of space figures and, hence, the study of which requires spatial reasoning. Consequently, abilities related to interpreting various representations and switching from one vector coordinate system to another are considered very important in problem-solving. Thus, it is presumed that a correct interpretation and creation of representations promotes problem-solving in vector calculus [46 61].

Although considering populations and mathematical contexts markedly different from the preservice college students and vector calculus in this study, numerous studies have attempted to establish how SV ability supports mathematical aptitude and to connect cognitive skills, mathematical processing, and mathematical aptitude [8, 36, $41,59]$. For instance, it is evidenced that the development of "arithmetic sense" and spatial thinking are closely linked [40, 49]. Additionally, it is claimed that early spatial intelligence predicts children's performance in mathematics [8, 36, 41, 59] and that children with better visual relationships develop stronger mathematics abilities in the lower grades [21, 59]. Another study with three-year-olds found evidence that spatial skills were even more important than early mathematics skills in predicting mathematics achievement at the age of five [17]. Contradicting others [17, 64], it was noted that the level of SV is independent of gender [50].

Others have [17,9] directly link family social economic status (SES) and children's mathematics achievement to the family's geographical settlement. Research [56] further the notion by hypothesising that poor family SES affect children's cognitive development. Hence, it is argued that students who grow up in high-poverty rural settlements perform more poorly in cognitive activities such as SV skills and problem 
solving compared to their more affluent counterparts. Thus, it is worth inquiring as to whether one's environment has direct correlation with spatial reasoning, cognitive skills, and mathematical aptitude and if any effects remain through collegiate learning.

Research indicating that SV skills is trainable through activity such as mental rotation tasks $[8,57]$ provides encouragement regarding the potential enhancement of the cognitive skills of students from low SES. Researchers [57 17] maintain that children from higher SES develop stronger arithmetic abilities in their early stages through SV interactions.

Of the numerous spatial skills studied, mental rotation has seemingly gained most attention from researchers $[8,57]$. Mental rotation is defined as the ability to rotate, manipulate, and visualise $2 \mathrm{D}$ or $3 \mathrm{D}$, either physically or mentally. Individuals' spatial reasoning ability is measured using cognitive tasks such as mental rotation [48, 47], mental paper folding [47] and Purdue visualisation rotation [23]. Subsequently, individuals who score high on these tests are arguably considered to have better spatial reasoning. Some $[17,8]$ advance the notion that mental rotation skills are a predictor of children's mathematics achievement (rotation of 2D or 3D objects).

While mental rotation has been widely used in studying SV skills because it is thought to tap into a key aspect of such abilities $[17,8,26]$ the precise relationship (i.e., mechanism) between mental rotation and visual spatial abilities is still unknown. It [62] has been found that four-year-olds who created complex block structures representing a play theme (such as a castle, PlayStation, and space station) demonstrated greater knowledge of mathematics and achieved higher grades in both middle school (seventh grade) and high school. The analogy of physical rotation of 2D or 3D shapes and mental rotation has made it conceivable to use varying degrees of rotation, accuracy, and time-to-completion as measures of individual differences in mental rotation ability.

\subsection{The MATLAB as a pedagogical in vector calculus}

Educators, learners, and parents by default ought to comprehend through CAT, a form of e-learning; what their children learn, particularly in respect to geometry content and pedagogy, or geometry epistemology the learners demonstrate. Dynamic software such as the MATLAB (Matrix LABoratory) can afford the opportunity to enhance mathematical cognition [39]. The current research adapts MATLAB because MATLAB performs a wide variety of plots and curves, including 2D plots, 3D plots, $3 \mathrm{D}$ surface plots, and allows the user to efficiently manipulate vectors and matrices. The authors of the current research use MATLAB to provide an interactive teaching and learning environment allowing the user to perform a range of mathematical activities from simple arithmetic to more complex investigations such as Reiman integrals. The choice for employing MATLAB in this study was also anchored upon previous studies [32, 3, 16, 15], who noted that static drawings of a solid region on twodimensional paper contributes to students' difficulties in interpreting static diagrams representing three-dimensional geometric objects. Consequently, sketching 3D solid figures is cognitive demanding and requires high SV skills. 
Vector operations, such as addition, subtraction, multiplication, dot and cross products, gradient, divergence, and curl, form the basis of vector calculus. Force, electric fields, momentum, and magnetic fields are just a few examples that can be represented by vector diagrams. Altogether, this evidence why vector calculus is often considered to be a very visual subject demanding students' high SV reasoning in problem-solving. For instance, vector operations such as gradient of a vector, curl, and divergence by their definitions require SV skills and analytical reasoning in performing related tasks. For instance, the vector operator curl of the vector $\vec{F}$ represented as $\nabla \vec{F}$ measures how much a vector field circulates around a given a point as given in the illustrative example 1. Illustrative example 1; With the aid of sketch evaluate the curl of the vector function $\vec{F}=-y_{i}+x_{j}$. We first of all calculate the determinant to represent the curl.

$$
\operatorname{Cur} \vec{F}=\nabla \times \vec{F}=\left[\begin{array}{ccc}
i & j & k \\
\frac{\partial}{\partial x} & \frac{\partial}{\partial y} & \frac{\partial}{\partial z} \\
-y & x & 0
\end{array}\right]=2 k
$$

Hence, the $\operatorname{Cur} \vec{F}=\nabla \times \vec{F}=2 k$ can be represented as shown in Figure 1(a) and $1(\mathrm{~b})$

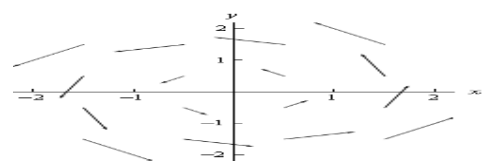

(a) Figure-a shows the curl of the vector function $\overrightarrow{\boldsymbol{F}}=-\boldsymbol{y}_{\boldsymbol{i}}+\boldsymbol{x}_{\boldsymbol{j}}$

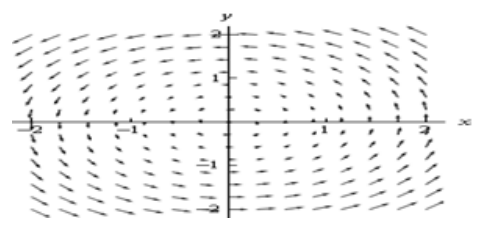

(b) Vector function $\overrightarrow{\boldsymbol{F}}=-\boldsymbol{y}_{\boldsymbol{i}}+\boldsymbol{x}_{\boldsymbol{j}}$ generated using the MATLAB

Fig. 1.

Figures 1(a) and 1(b) show a free hand sketch and MATLAB display of the vector equation $\overrightarrow{\boldsymbol{F}}=-\boldsymbol{y}_{\boldsymbol{i}}+\boldsymbol{x}_{\boldsymbol{j}}$ respectively. From observation, MATLAB shows many vector fields and depicts the exact direction of the vector equation.

The choice for MATLAB in this study has largely been informed by the fact that studies have adequately proven that dynamic software, like MATLAB and its computer environments is positively linked to students' increase in SV and mathematics problem-solving [34, 8, 14]. MATLAB's interactive graphical user interface (GUI), animation, and graphics visualisation capabilities are connected to students' cognitive 
development and growth in mathematical reasoning, logical reasoning, and problem solving [5, 43]. A growing body of literature from both mathematics and physics education reveals that students struggle with vector operations such as vector arithmetic, dot and cross products, gradient, divergence, and curl, which are the fundamentals when learning vector calculus [12]. Therefore, we anticipate that the use of the MATLAB as a pedagogical tool for teaching and learning in a traditional classroom would enhance students' SV skills and problem-solving in vector calculus.

\section{Theoretical Framework}

Authors [1, 2] define visualisation as, "the ability, the process and the product of creation, interpretation, use of and reflection upon pictures, images, diagrams in our minds, on paper or with technological tools, with the purpose of depicting and communicating information, thinking and developing previously unknown ideas and advancing understandings." Different theoretical frameworks (models - in this research theoretical framework and models are used interchangeably) have been used to explore the way in which spatial visualisation influences problem-solving [1, 63]. For instance, Duval's $[13,14]$ semiotic theory proposes cognitive processes for interpreting mathematical symbols. This current study employs the Visual-Analyser (VA) model developed by Zazkis [63], to explore the role of spatial visualisation in problem-solving in vector calculus. The VA model views visual and analytical cognition as both iterative and complementing each other in the problem-solving process. As suggested by the model, the process begins with an act of visualisation, $V_{1}$ which could be any visual representation (drawing, image on the computer screen or mental image). Using the model, the image may be analysed during stage $A_{1}$ which consists of some sort of coordination of the objects and processes constructed in step $V_{1}$. This analysis may lead to new constructions. In a subsequent act of visualisation, $V_{2}$, the student returns to the same "picture" object used in $V_{1}$, but as a result of the analysis in $A_{1}$, the picture may change. As the sequence is repeated, each act of analysis is dependent on the previous act of visualisation.

While various learning technologies have mushroomed as characterized by the literature review and substantiated by the theoretical review, there remain opened question: Thus, altogether, while extant research evidence that learning enhancement through technological tools does help, there are still questions in many disciplines regarding the adoption of learning technologies.

\subsection{Research questions}

In respect to $(\mathrm{A})$ pre-service teachers' participants at the (B) research university situated in a high-poverty, rural region of South Africa, with (C) a control group experiencing lectures and the experimental group experiencing MATLAB-based learning activities (D) in the context of vector calculus: 1. Do the different learning experiences lead to differences in student work regarding visual and analytical cognition (e.g., number of observable occurrences, frequency of iterations, and the complementary nature of the two)? 2. Does differences from \#1 lead to: stronger SV skills, deeper 
mathematical understanding, greater conceptual understanding, and better problem solving? Examining these questions in South African rural schools has thus become relevant. Compelling even the public to take more elementary roles in educating their children. For instance, as educators and parents work with their children, both may observe several mathematical content issues that may increase learners' performance in a way different from before through CAT. The current research highlights the fact that geometry content and pedagogy, or geometry epistemology are not the same through CAT and particularly in virtual environment. Thus, assisting all to best assist students.

\section{$4 \quad$ Methodology}

The research adopted Duval semiotic theory proposes cognitive processes. A response to the research leads to number of research questions. Together with theoretical framework and research questions, there are number of methodological steps: The research randomly sampled 100 preservice teachers in second year vector calculus class in a South African university located in a high-poverty and rural region of the nation. Almost all the participants $(\mathrm{N}=94)$ were also from high-poverty, rural regions in South Africa. While primarily homogeneous on race (all Black South African), ethnicity (heavy Zulu influence) and socioeconomic status, the participants were heterogenous on academic performance levels, mathematical performance in the respective class and in previous classes, and gender. These participants were separated into an experimental group $(\mathrm{N}=50)$ and a control group $(\mathrm{N}=50)$. A mixed method approach was employed in the study. A pre-test was administered to determine and compare the baseline for each group. As later revealed in the findings, both groups were of very similar ability levels at the outset of the study. The groups were taught by the same researcher for three weeks on the vector calculus topics: addition and subtraction of vectors, dot and cross products, curl and vector integration. For the control group, lessons were taught using the traditional approach using textbooks and chalkboard, and 3D shapes associated with vector integration were drawn on the board and explanations were given. However, for the experimental group the dynamic visual tool MATLAB was employed as a pedagogical tool in lesson delivery. The same instructor was employed for both the control and experimental groups to maintain some consistent characteristics. For instance, although the instructional strategies were different between the groups, the instructor/student interaction and dynamic would be more consistent than not. Additionally, employing one instructor ensured that the proposed content for each group was covered as intended.

It is important to further explicate the significant differences in the instructional methodologies between the two groups. While the content covered in the two groups was as identical as possible, the control group experienced lectures with the aids of static diagrams. For the experimental group, the first week involved training on the usage of the MATLAB by the researcher. In the following two weeks, instruction was provided through lectures accentuated with dynamic applets in MATLAB and learning was experienced through activities developed to be investigated through MATLAB use. Comparatively, the control group experienced three weeks of lectures 
involving static diagrams through which to visualize the content. Thus, there are numerous variables which cannot be disaggregated from the differences in the treatments. It is not simply that one group used MATLAB and the other did not. Rather, the group which used MATLAB also experienced learning through carefully designed learning activities rather than the lecture, practice, homework cycle. Notably, neither group experienced collaborative learning in this project. This was purposely planned in this manner so to eliminate this as another possibly confounding variable.

Both the pre-test and post-test were provided on paper and completed with pen or pencil. No use of MATLAB was allowed in completing these tests. Data was collected quantitatively through a pre-test and a post-test and qualitatively through content analysis of student work on the test items. The statistical method, independent sampled t-test was employed to determine whether there was significant difference between the results from the groups. The analysis involved considering by a brief cognitive skill each item strives to examine, the problem-solving skills (i.e., conceptual understanding, procedural skills, and factual knowledge) demonstrated by the student, and the type of coordination processes involved in the problem-solving situation. The pre-test (same as post-test) consisted of eight items.

In the following reporting, student work is coded as CGxxx or EGyyy, with CG and EG denoting whether the student belonged to the control or experimental group respectively. The numerals xxx and yyy denote the participant. It is important to recognize that only a few exemplars are provided from the collected and analyzed work of the 100 participants. Providing significantly more examples would be both voluminous and pedantic.

\subsection{Laboratory activities}

Students in the experimental group were given one-week training on the usage of the MATLAB by the researcher followed by activities relating to vector calculus such as generating and viewing isometric blocks from different angles, plotting vector fields, and many more (as illustrated in Figures a, b and c).

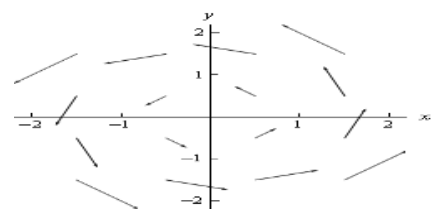

(a) Figure-a shows the curl of the vector function $\overrightarrow{\boldsymbol{F}}=-\boldsymbol{y}_{\boldsymbol{i}}+\boldsymbol{x}_{\boldsymbol{j}}$

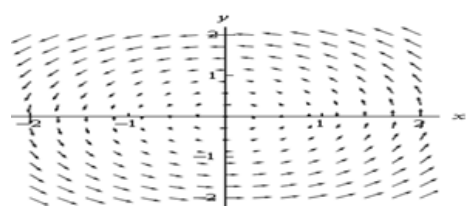

(b) Vector function $\overrightarrow{\mathbf{F}}=-\mathbf{y}_{\mathbf{i}}+\mathbf{x}_{\mathbf{j}}$ generated using the MATLAB 


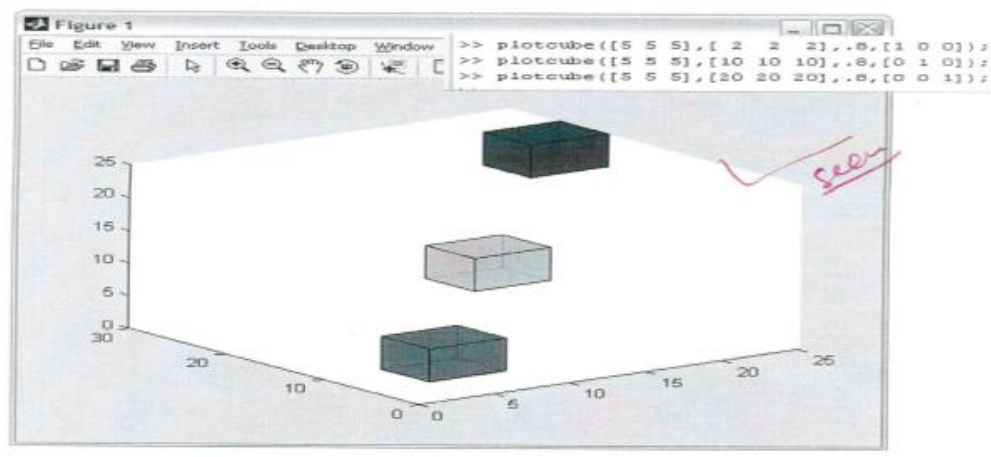

(c) Isometric view of blocks.

Fig. 2. A worksheet presented by student (EG014) from the experimental class who used the MATLAB to generate cube boxes.

In activities 1 and 2, the students in the experimental group used MATLAB to generate and rotate 3D shapes (e.g., such as a cube). The aim was to visualise, view 3D figures from different angles and make their own conjectures about the properties of 3D shapes. These activities (i.e., refer to Figures a and b) are presumed to have direct link with students' cognitive reasoning such as problem solving.

Activity 3

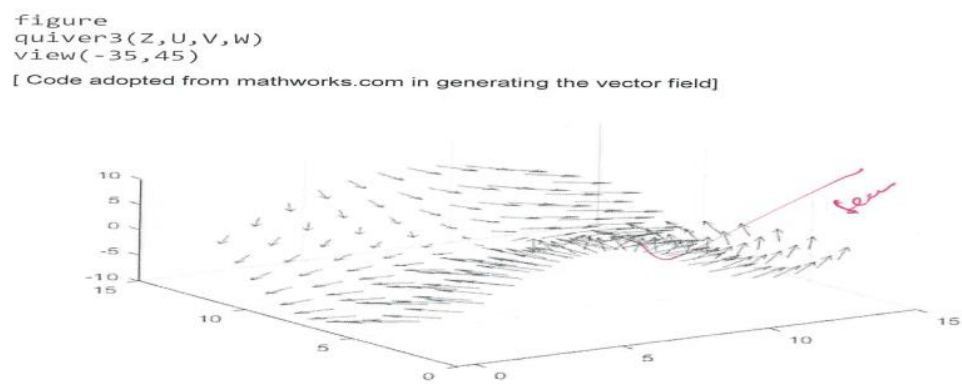

Fig. 3. A worksheet presented by student (EG015) from the experimental class run the code given to generate vector field.

The aim of activity 3 was to equip the experimental students on how to use MATLAB to generate vector field from any given vector equations (refer to Figure 3). This contributes to their ability to visualise a vector field and perform vector operations such as additions of vectors, flux, and cross product. The practical assistance of MATLAB to generate a vector field from a vector equation was aimed at improving the students' understanding, confidence, and visual reasoning. Furthermore, the use of MATLAB was planned to equip the students to visualise or sketch a correct vector field and give correct interpretations of the vector field drawn. 


\section{$5 \quad$ Findings}

Question 1 requires participants to match the equations with their respective graphs. This question was designed for students the need to employ visual and analytical cognition both iteratively and complementarily in ways which would be observable through their work and sought to examine the participants' SV skills and factual knowledge. Table 1 provides the percentage correct scores by both groups before the teaching experiment.

Table 1. The analysis of question 1 in percentage before the teaching experiment.

\begin{tabular}{|c|c|c|}
\hline Question & $\begin{array}{c}\text { Percentage scored by the control } \\
\text { group }(\boldsymbol{\%})\end{array}$ & $\begin{array}{c}\text { Percentage scored by the exper- } \\
\text { imental group (\%) }\end{array}$ \\
\hline $1.1 \frac{x^{2}}{a^{2}}+\frac{y^{2}}{b^{2}}+\frac{z^{2}}{c^{2}}=1$ & 28 & 28 \\
\hline $1.2 z=x^{2}+y^{2}$ & 29 & 27 \\
\hline $1.3 x y=3$ & 73 & 71 \\
\hline $1.4 y=x^{3}$ & 74 & 72 \\
\hline $1.5 x^{2}+y^{2}=3$ & 28 & 28 \\
\hline
\end{tabular}

QUESTION 1

MATCH EACH OF THESE EQUATIONS WITH ITS GRAPHS (A, B, C, D AND E) AND WRITE ONE STATEMENT FOR THE CHOICE OF YOUR ANSWER IN THE BOX PROVIDED BELOW EACH QUESTION.

$1.1 \frac{x^{2}}{a^{2}}+\frac{y^{2}}{b^{2}}+\frac{z^{2}}{c^{2}}=1$

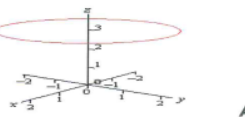

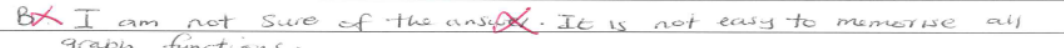

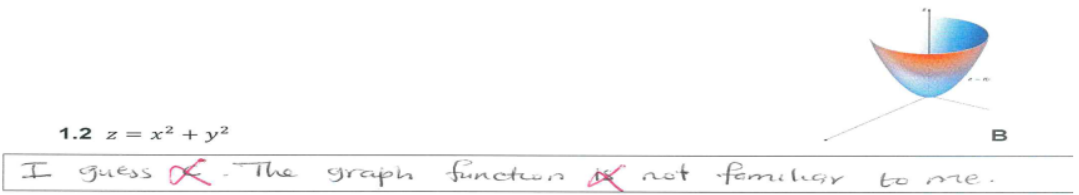

Fig. 4. The solution presented by CG005

Figure 4 shows the solution presented by CG005 and some of the general concerns raised. For instance, CG005 raised the concern that, since s/he did not often work with these algebraic equations, s/he found it difficult to match them to their respective graphs. S/he further claimed that "it is not easy to memorise all the equations and their graph functions."

Question 2a was meant to evaluate how participants integrate spatial-visualisation skills and analytical reasoning in sketching vector diagrams articulating correct representations of vector magnitude, direction, and interpreting vector correctly. This schema was used to consider the solution presented by the student CG0012. 


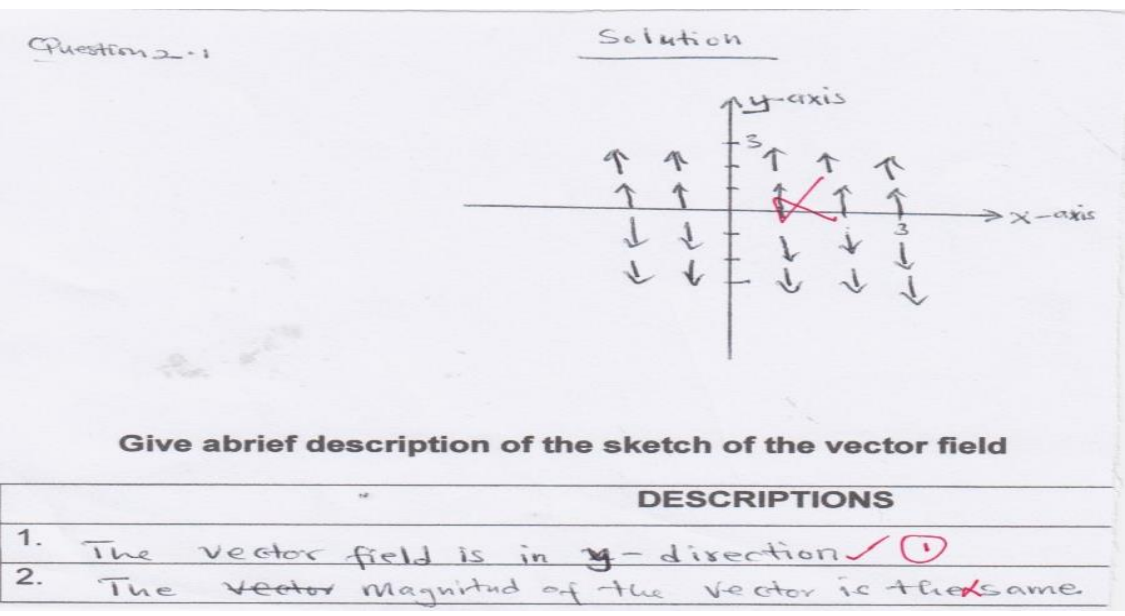

Fig. 5. Student CG012's solution on graph functions

Table 2. Analysis of the Visual-Analysis in the solution by CG012.

\begin{tabular}{|l|l|}
\hline \multicolumn{1}{|c|}{ Visual } & \multicolumn{1}{c|}{ Analysis } \\
\hline V1. Question 2.1a vector field sketch & Analysis \\
\hline V2. Visual step: setting the Cartesian plane & A1. Algebraic step: reading the vector function \\
\hline V3. Represent the vector in the $y$-axis & $\begin{array}{l}\text { A2. Read the vector function } \vec{F}(x, y)=x \vec{\jmath} \text { on } \\
\text { the } y \text {-axis. }\end{array}$ \\
\hline V3. Sketch for vector field & $\begin{array}{l}\text { A3. Error. Wrongful vector field representation } \\
\text { for both positive and negative } y \text {-axes. }\end{array}$ \\
\hline V4. Sketch shows magnitude and direction. & $\begin{array}{l}\text { A4. Error. The magnitude of the vector field } \\
\text { drawn is the same even as they further away } \\
\text { from the origin. }\end{array}$ \\
\hline
\end{tabular}

The solution presented by participant CG012 in Table 2, indicates that s/he was able to adhere to factual knowledge by recalling that the vector value $\vec{F}(x, y)=x \vec{\jmath}$ is in the $y$-axis. However, s/he was unable to recall that the length of the vector represents the magnitude. (The visual representation of the vector field must show an increase in length as the vector field is further away from the origin of the $x y$ plane.) This error showed a lack of both conceptual understanding and factual knowledge. This demonstrated that CG012 did not use visual and analytical cognition iteratively to refine each other.

Responses from another participant, EG012, on sketching vector field for the vector equation $\vec{F}(x, y)=x \vec{\jmath}$ (refer to Table 2) included: "vector field lines are not to get closer to each other", "the same distance is maintained between vector field lines", and "vector field lines move in upward directions and downwards in the Cartesian plane."

Question 2.1b examines participants' ability to convert word problems to algebraic equations. This question was again designed to observe participants' use of visual and analytical cognition. While most students did not attend to question $2.1 \mathrm{~b}$, the responses from CG022 included: "I found it difficult to write mathematics word problem" 
and "I normally ignore word problem because it is too challenging" (refer to Figure $6)$.

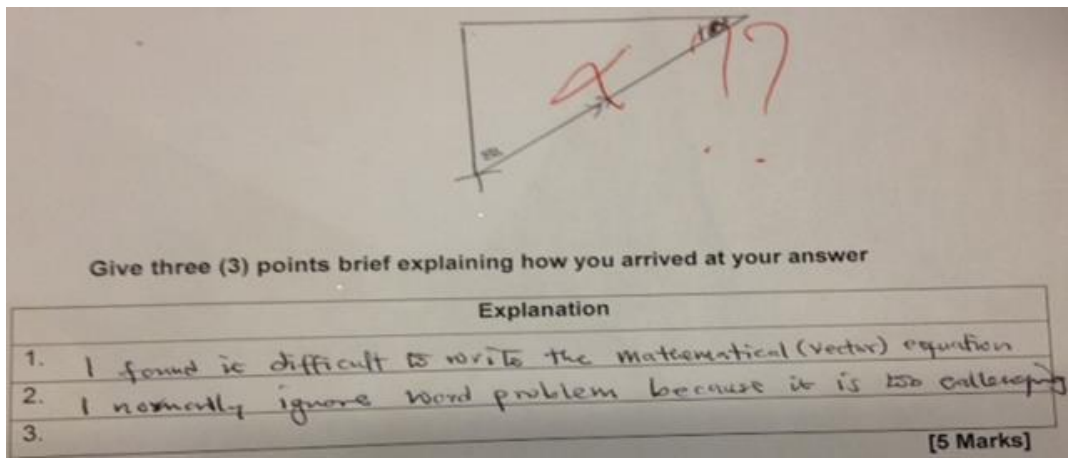

Fig. 6. CG022's solution for the word problem

Table 3. Analysis of the Visual-Analysis in the solution of CG022.

\begin{tabular}{|l|l|}
\hline \multicolumn{1}{|c|}{ Visual } & \multicolumn{1}{|c|}{ Analysis } \\
\hline $\begin{array}{l}\text { V1. Question 2.1b } \\
\text { Visual step: Wrongful representation of vector diagram } \\
\text { to the question }\end{array}$ & \begin{tabular}{l}
\multicolumn{1}{|c|}{ A1. Algebraic step: wrongful writing of equation. } \\
A2. Wrongful vector calculation.
\end{tabular} \\
\hline
\end{tabular}

From the solution presented and the table of visual-analysis (refer to Figure 6 and Table 3), the CG022 failed to represent the word problem. This led to his/her inability to write the correct equation. This was interpreted to mean that s/he most likely lacked the conceptual understanding and spatial-visualisation skills required for the sketching and writing of the vector diagram for the word problem (refer to Figure 6).

Question 2.2a and 2.2b asked participants to convert the Cartesian coordinate $(x, y, z)=(1, \sqrt{3}, 2)$ to cylindrical coordinates, a process again requiring both visual and analytical cognition iteratively and complementarily. To provide a solution for 2.2a, procedural skills are required. This 'routine type of question' required participants to write the cylindrical coordinate equations, substitute the Cartesian coordinate points, and compute the cylindrical coordinates. Question $2.2 \mathrm{~b}$ (sketching the cylindrical coordinate points calculated in question 2.2a) required students' SV skills. This scheme was then compared with the solution presented by participant EG009. 


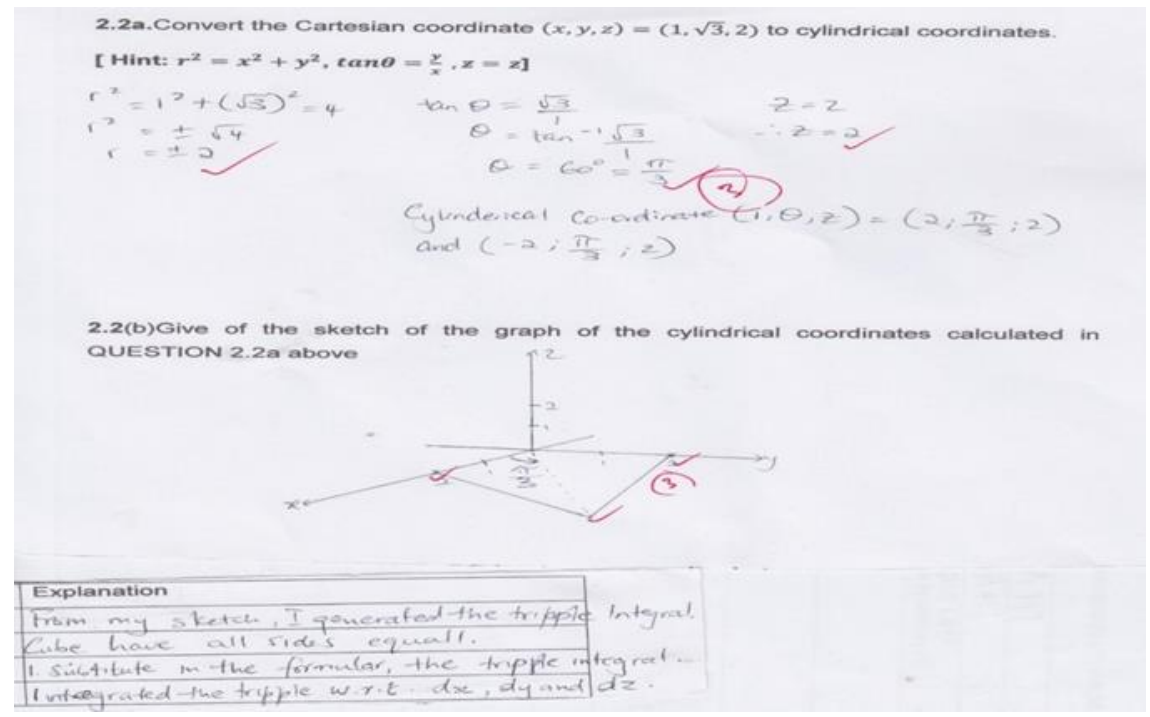

Fig. 7. EG009's solution for the conversion of the Cartesian coordinate $(x, y, z)=(1, \sqrt{3}, 2)$ to cylindrical coordinates and a graph in cylindrical coordinates.

Table 4. Analysis of the Visual-Analysis in the solution by EG009.

\begin{tabular}{|l|l|}
\hline \multicolumn{1}{|c|}{ Visual } & \multicolumn{1}{|c|}{ Analysis } \\
\hline $\begin{array}{l}\text { 2.2a \& 2.2b conversion between Cartesian to } \\
\text { cylindrical coordinate system. Visual steps }\end{array}$ & Algebraic steps \\
\hline $\begin{array}{l}\text { 2.2a Numerical register: copying the equation } \\
\text { and substituting into the cylindrical coordi- } \\
\text { nate equations. }\end{array}$ & $\begin{array}{l}\text { A1. Coordinate points were substituted in the cylindrical } \\
\text { coordinate equations } r^{2}=x^{2}+y^{2}, n \theta=\frac{y}{x}, z=z . \\
\text { A2. Calculation computed and cylindrical coordinates was } \\
\text { found. }\end{array}$ \\
\hline $\begin{array}{l}\text { 2b. V1. Geometric register: Set up the } \\
x, y, \text { and } y \text { plane. }\end{array}$ & $\begin{array}{l}\text { A3. Algebraic register: Coordinate points plotted on the } \\
x, y, \text { and } y \text { plane correctly. }\end{array}$ \\
\hline $\begin{array}{l}\text { V2. Joining the cylindrical coordinate points } \\
\text { correctly to form the 3D shape. }\end{array}$ & \\
\hline
\end{tabular}

Figure 7 and Table 4 indicate that participant EG009 correctly employed procedural skills (e.g., analytical step substituting into the cylindrical equations correctly). Conceptual understanding was demonstrated by the student producing a correct conversion between geometric and algebraic registers. It can be interpreted that participant EG009 demonstrated coordination between spatial and analytical thinking.

In providing the solution for question 3.1 the student had to apply his/her spatialvisualisation skills, conceptual understanding, and procedural skills. S/he needed to find $x, y$, and $z$ intercepts from which s/he could write the cartesian coordinate points; this required both conceptual understanding and procedural skills. Furthermore, setting up the $x, y, z$ cartesian plane and plotting cartesian coordinate points to form a tetrahedron $3 \mathrm{D}$ shape required spatial-visualisation skills. This scheme was then used to analyse the solution presented by participant EG043. 


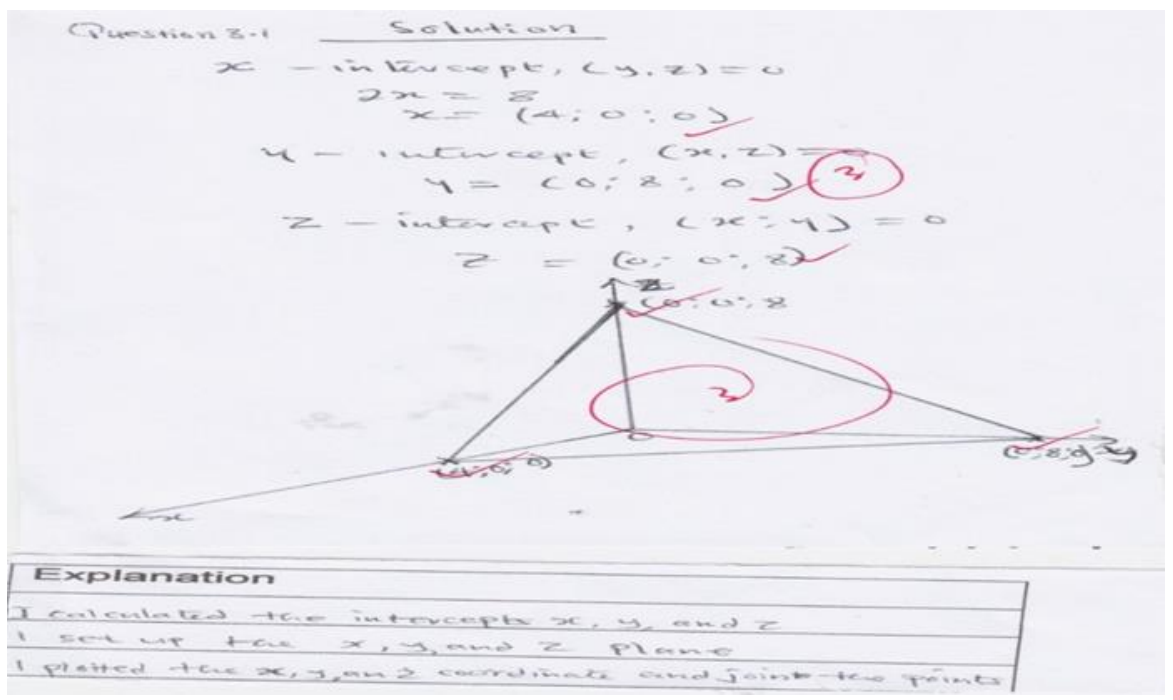

Fig. 8. EG043's solution for sketching the 3D shape of the algebraic equation $2 x+y+z=8$ in the $\mathrm{D} \mathrm{E}$

Table 5. Analysis of the Visual-Analysis in the solution by EG043.

\begin{tabular}{|l|l|}
\hline \multicolumn{1}{|c|}{ Visual (V) } & \multicolumn{1}{|c|}{ Analysis (A) } \\
\hline 3.1 Multivariate calculus Visual steps & Analysis \\
\hline $\begin{array}{l}\text { V1. Numerical register: find the coordinate } \\
\text { points for plotting the graph of the equation } \\
2 x+y+z=8 .\end{array}$ & A1. Algebraic register: Calculation of $x, y$, and $y$ intercepts. \\
\hline $\begin{array}{l}\text { V2. Geometric register: Correct setup of the } \\
x, y, \text { and } y \text { cartesian plane. }\end{array}$ & $\begin{array}{l}\text { A2. Calculation of } x, y \text {, and } y \text { intercepts and writing the } \\
\text { coordinate. }\end{array}$ \\
\hline $\begin{array}{l}\text { V3. Sketch of the coordinates points to form } \\
\text { the 3D shape. }\end{array}$ & $\begin{array}{l}\text { A3. Coordinate points indicated on the } x, y \text {, and } y \text { plane } \\
\text { correctly. }\end{array}$ \\
\hline
\end{tabular}

Question 3.2 required participants to first recall (factual knowledge) that the equation $h(x)=2 x$ is a straight-line graph and $g(x)=x^{2}$ is a parabolic graph and sketch or visualize the region bounded by the two function graphs (spatial-visualisation skills). This was to be followed by writing the double integral equation for the region bounded by the graph functions and computing the area which required both conceptual understanding and procedural skills. This scheme was then used as guide in analysing the solution presented by CG016. 


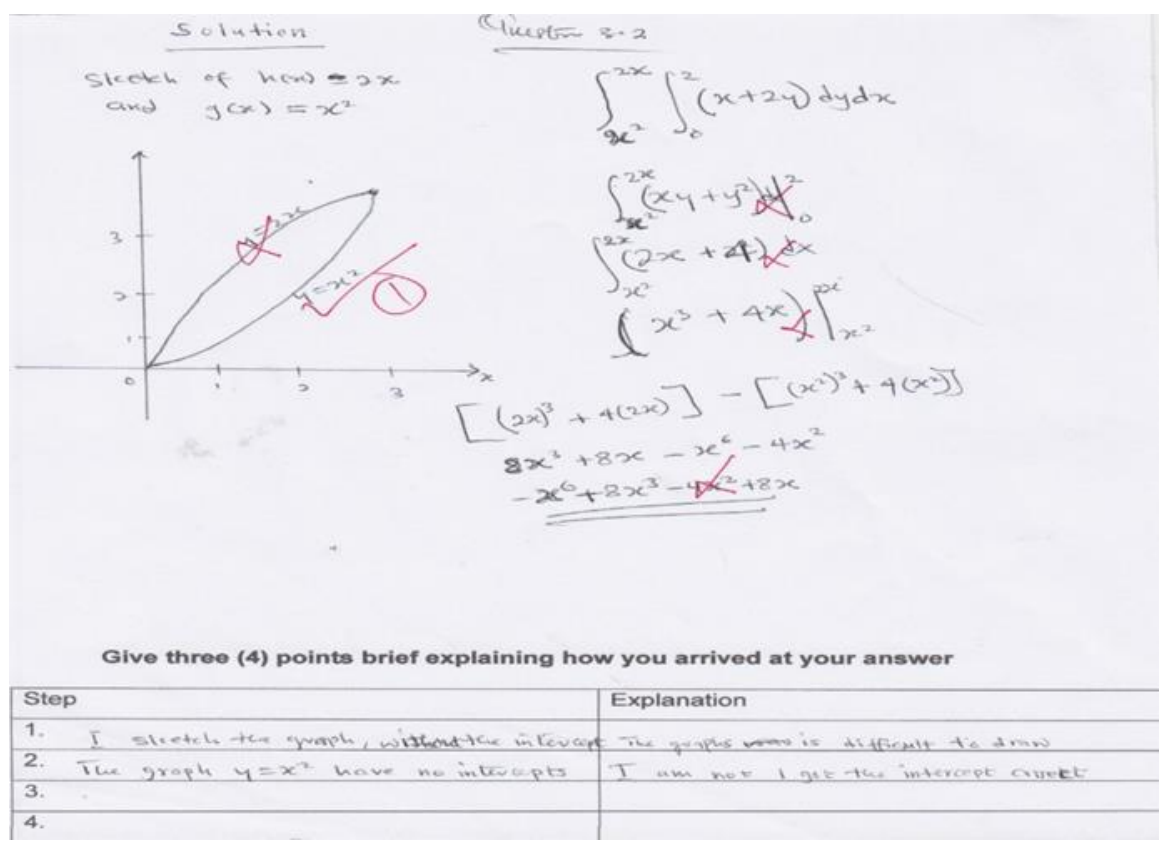

Fig. 9. CG016's solution for sketching the graph of the region $R$ bounded by $h(x)=2 x$ and $g(x)=x^{2}$, and evaluating $\iint_{R}(x+2 y) d y d x$ along the $R$ in the interval $0 \leq x \leq 2$.

Table 6. A scrutiny of the Visual-Analysis in the solution by CG016.

\begin{tabular}{|l|l|}
\hline \multicolumn{1}{|c|}{ Visual (V) } & \multicolumn{1}{|c|}{ Analysis (A) } \\
\hline 3.1 Question on Double integral Visual steps & Analysis \\
\hline $\begin{array}{l}\text { V1. Conversion: Algebraic registrar to geo- } \\
\text { metric registers: } h(x)=2 x \text { and } g(x)=x^{2} .\end{array}$ & $\begin{array}{l}\text { A1. Treatment of algebraic functions } h(x)=2 x \text { and } \\
g(x)=x^{2} \text { is equated to zero find their intersection. }\end{array}$ \\
\hline $\begin{array}{l}\text { V2. A correct sketch of } g(x)=x^{2} \text { but incor- } \\
\text { rect representation of the linear graph } h(x)= \\
2 x .\end{array}$ & $\begin{array}{l}\text { A2. Error: Incorrect setup of the double integration. } \\
\text { A3. Incorrect calculation and appear not sure. } \\
\text { A4. Unable to calculate the intersection of the two func- } \\
\text { tions } h(x)=2 x \text { and } g(x)=x^{2} \text { correctly. }\end{array}$ \\
\hline
\end{tabular}

Finally, the last question 3.3 required a sketch or imagery of the $3 \mathrm{D}$ cube shape (spatial-visualisation skills) and one had to recall that the dimensions of a cube are equal (i.e., factual knowledge). This is followed by writing the triple integral equation and computing the mass and as such requires students' conceptual understanding and procedural skills. This scheme was used to analyse the solution presented by EG036. 


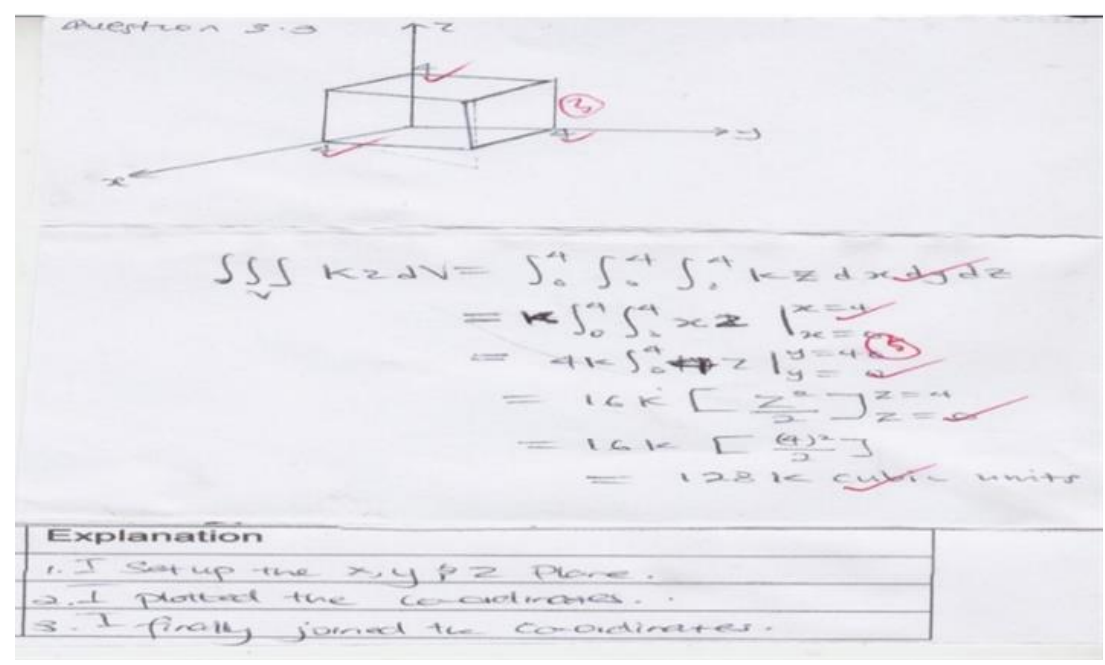

Fig. 10.Student EG036's solution for the calculation the mass of a cube with density of $f(x, y, z)=t z$

Table 7. A close scrutiny of the Visual-Analysis in the solution by EG036.

\begin{tabular}{|l|l|}
\hline \multicolumn{1}{|c|}{ Visual } & \multicolumn{1}{c|}{ Analysis } \\
\hline $\begin{array}{l}\text { Q.3.3 Triple integral } \\
\text { Visual steps }\end{array}$ & Analysis steps \\
\hline $\begin{array}{l}\text { V1. Conversion from Algebraic to geo- } \\
\text { metric register. }\end{array}$ & A1. Treatment in algebraic register. \\
\hline $\begin{array}{l}\text { V2. Correct sketch of cube in the } x, y, \\
\text { and } z \text { plane }\end{array}$ & $\begin{array}{l}\text { A2. Assigned correct dimension to the cube. } \\
\text { A3. Generate triple integral. } \\
\text { A5. Correct substitution of lower and upper limits. }\end{array}$ \\
\hline
\end{tabular}

Based on the analysis (Table 7) and the solution presented, participant EG036 (refer to Figure 10) demonstrated a high sense of smooth coordination between visual and analytical reasoning. By sketching correctly, a 3D cube figure and indicating the dimensions to represent the problem situations, factual knowledge was demonstrated. Furthermore, s/he demonstrated both conceptual knowledge and procedural skills having correctly generated the triple integral equation, indicated lower and upper limits, and performed the calculations of the volume of the cube.

$8 \mathrm{a}$ and $8 \mathrm{~b}$ give a summary of the group statistics and the independent sample test of the pre-test.

Table 8. a: Group statistics on pre-test

\begin{tabular}{|c|l|c|c|c|c|}
\hline \multirow{3}{*}{$\begin{array}{c}\text { Pre-Test } \\
\text { Score }\end{array}$} & \multicolumn{1}{|c|}{ Group } & N & Mean & Std. Dev & Std. ErrMean \\
\cline { 2 - 6 } & Control Group & 50 & 14.62 & 3.78 & .535 \\
\cline { 2 - 6 } & Exp Group & 50 & 15.40 & 3.65 & .516 \\
\hline
\end{tabular}

$\mathrm{p}<0,05$ 
The pre-test was administered to 100 rural-based pre-service teachers constituted of control $(\mathrm{N}=50)$ and experimental groups $(\mathrm{N}=50)$ as indicated in Table 8a. The mean pre-test score of the control group $(\bar{x}=14.62, S D=3.784)$ and that of mean pre-test score for the experimental group $(\bar{x}=15.40, S D=3.648)$. An independent sampled test was further carried out to see whether there was significant difference of the pre-test score between the two groups (refer to Table $8 \mathrm{~b}$ ).

Table 8. b: Independent Sample Test for assessing the baseline of the groups

\begin{tabular}{|c|c|c|c|c|c|c|c|c|c|c|}
\hline & \multicolumn{2}{|c|}{$\begin{array}{c}\text { Levene's Test } \\
\text { for Equality of } \\
\text { Variances } \\
\end{array}$} & \multicolumn{7}{|c|}{ t-test for Equality of Means } \\
\hline & & \multirow[t]{2}{*}{$\boldsymbol{F}$} & \multirow[t]{2}{*}{ Sig. } & \multirow[t]{2}{*}{$T$} & \multirow[t]{2}{*}{$D f$} & \multirow[t]{2}{*}{$\underset{\text { (2-tailed) }}{\text { Sig. }}$} & \multirow[t]{2}{*}{$\begin{array}{c}\text { Mean } \\
\text { Diff }\end{array}$} & \multirow[t]{2}{*}{$\begin{array}{c}\text { Std. Err } \\
\text { Diff }\end{array}$} & \multicolumn{2}{|c|}{$\begin{array}{l}95 \% \text { confidence } \\
\text { interval of the } \\
\text { Diff }\end{array}$} \\
\hline & & & & & & & & & Lower & Upper \\
\hline \multirow{2}{*}{$\begin{array}{l}\text { Pre - } \\
\text { Test } \\
\text { Score }\end{array}$} & $\begin{array}{l}\text { Equal variances } \\
\text { assumed }\end{array}$ & .51 & .48 & -1.05 & 98 & .29 & -.78 & .74 & -2.26 & 695 \\
\hline & $\begin{array}{l}\text { Equal variances } \\
\text { not assumed }\end{array}$ & & & -1.05 & 97.9 & .29 & -.78 & .74 & -2.26 & 695 \\
\hline
\end{tabular}

T-Value significant at $p<0.05$

From Table $8 \mathrm{~b}$, the mean difference between the groups was 0.78 with a t-value 1.05. However, the $p$-value (2-tailled) was $0.29(p>0.05)$; hence, we have reason to conclude that there was no significant difference between the mean pre-test score of the control group and the experimental group. This meant that control and experimental groups were both on a similar baseline before the teaching experiment (treatment).

Table 9. a: Summary of group statistics and the Independent Sample Test on the post-test.

\begin{tabular}{|c|l|c|c|c|c|}
\hline \multirow{3}{*}{ Post-Test Score } & \multicolumn{1}{|c|}{ Group } & Number & Mean & Std. Dev & Std. ErrMean \\
\cline { 2 - 6 } & Control Group & 50 & 22.20 & 3.169 & .448 \\
\cline { 2 - 6 } & Exp Group & 50 & 29.12 & 3.274 & .463 \\
\hline
\end{tabular}

From Table 9a, the mean post-test score of the experimental group was $(\bar{x}=$ $29.12, S D=3.27)$ and the mean post-test score of the control group $(\bar{x}=$ $22.20, S D=3.169)$. This showed there was an increase in achievement test after the two teaching experiments (i.e., the use of MATLAB as a tool in teaching and learning versus a traditional lecture-based teaching approach) compared to the baseline assessment test (pre-test) which was for the control $(\bar{x}=14.62, S D=3.78)$ and for the experimental group $(\bar{x}=15.40, S D=3.65)$. An independent sample test was further carried out to find out whether there was significant difference between the groups (see Table 9b). 
Table 9. b: Independent sample test for achievement test on vector calculus (Post-test)

\begin{tabular}{|c|c|c|c|c|c|c|c|c|c|c|}
\hline & \multicolumn{2}{|c|}{$\begin{array}{l}\text { Levene's Test } \\
\text { for Equality of } \\
\text { Variances }\end{array}$} & \multicolumn{7}{|c|}{ t-test for Equality of Means } \\
\hline & & \multirow[t]{2}{*}{$F$} & \multirow[t]{2}{*}{ Sig. } & \multirow[t]{2}{*}{$T$} & \multirow[t]{2}{*}{$D f$} & \multirow[t]{2}{*}{\begin{tabular}{|c|} 
Sig. \\
(2-tailed)
\end{tabular}} & \multirow[t]{2}{*}{$\begin{array}{c}\text { Mean } \\
\text { Difference }\end{array}$} & \multirow[t]{2}{*}{\begin{tabular}{|l|} 
Std. Error \\
Difference
\end{tabular}} & \multicolumn{2}{|c|}{$\begin{array}{c}95 \% \text { confidence } \\
\text { interval of the } \\
\text { Difference } \\
\end{array}$} \\
\hline & & & & & & & & & Lower & Upper \\
\hline \multirow{2}{*}{$\begin{array}{l}\text { Post - } \\
\text { Test } \\
\text { Score }\end{array}$} & \begin{tabular}{|l|} 
Equal \\
variances \\
assumed
\end{tabular} & .239 & .626 & -10.739 & 98 & .000 & -6.920 & 644 & -8.199 & -5.641 \\
\hline & \begin{tabular}{|l} 
Equal \\
variances \\
not as- \\
sumed
\end{tabular} & & & -10.739 & 97.895 & .000 & -6.920 & 644 & -8.199 & -5.641 \\
\hline
\end{tabular}

T-value significant at $p<0.05$

Table $9 \mathrm{~b}$ shows a mean difference of 6.920 between the groups and the $p$-value 0.00 . The $p$-value was lower than the T-value significant $(p<0.05)$ in favour of the experimental group. The inference was that MATLAB facilitated student cognitive activities in the course while performing the laboratory activities as such generating geometric figures, rotating, and viewing them from different views, generating vector fields, etcetera. Also, it means the laboratory activities mediated coordination between spatial-visualisation and vector calculus achievement. Thus, MATLAB promoted the performance of the experimental group in vector calculus achievement test. Hence the use of this dynamic computer environment in teaching and learning in traditional classrooms enhanced mathematics problem-solving skills and achievement.

\section{Discussion}

Prior to considering other results of this research, it is important to return specifically to the visual-analysis model [63] supporting this study. General comparative observations between the work performed by students in the control group versus the experimental group can be made. First, students in the experimental group demonstrated a greater number of observable occurrences of both visual and analytical cognition. For instance, while many control group students exhibited one to three occurrences of each (e.g., A1, A2, A3 and V1, V2, V3, with means of A $=2.38$ and V = 2.56 occurrences respectively), many experimental group students exhibited three to five occurrences of each (e.g., A1,A2,A3,A4 and V1,V2,V3,V4, with means of A = 4.38 and $\mathrm{V}=4.19$ occurrences respectively). Second, a greater frequency of iterations occurred in the work of experimental group participants (e.g., V1-A1-V2-A2-V3-A3V4-A4) than for the control group (e.g., V1-A1-V2-A2). Third, far more often, the work from participants in the experimental group demonstrated observable occurrences in which visual and analytic notions complemented each other, building to spatialvisualization (SV) skills and conceptual understanding. In contrast, the work from control group participants and the experimental group demonstrated a greater frequency of observable occurrences in which visual and analytic notions competed and 
confounded each other, leading to errors regarding fact-based knowledge with limited conceptual understanding. Thus, for the experimental group, visualisation and analysis seemed to coordinate when solving mathematical tasks, leading to deeper SV skills and mathematical understanding.

The study set out to analyse how rural-based pre-service teachers apply their spatial-visualisation skills in problem-solving in vector calculus. The participants were randomly separated into control and experimental groups of equal size and similar ability (according to the pretest). Each group took the same pre-test prior to the teaching experiment and the same post-test after the teaching experiment. The tests were to determine the participants' conceptual understanding, procedural skills and factual knowledge required in vector calculus problem solving. In addition, guided by the visual analysis model from Zazkis [63], the participants' ability to coordinate between visual and analysis in solving vector calculus problem was analysed by closely scrutinising the solution presented.

Question 1 (refer to Figure 5) required participants to match some selected equations associated with vector calculus problems with their respective graphs. This required both students' conceptual understanding and factual knowledge. However, our findings revealed that participants struggled to link algebraic function to graph. From this perspective, rural-based teachers' inability to recall or sketch graph functions that are associated with vector calculus problem may be due to poor spatial reasoning skills. Interestingly, the computer dynamic environment plays a significant role in these conversions. By using MATLAB, the experimental group did not only become more familiar with 3D geometric shapes (such as; planes, 3D shapes such as ellipsoid, cone, cube, hyperboloid, and many more) but they were able to generate and display them on the screen.

Table 10. The analysis of question 1 in percentage after the teaching experiment.

\begin{tabular}{|c|c|c|}
\hline Question & $\begin{array}{c}\text { Percentage scored by the control } \\
\text { group (\%) }\end{array}$ & $\begin{array}{c}\text { Percentage scored by the exper- } \\
\text { imental group (\%) }\end{array}$ \\
\hline $1.1 \frac{x^{2}}{a^{2}}+\frac{y^{2}}{b^{2}}+\frac{z^{2}}{c^{2}}=1$ & 56 & 75 \\
\hline $1.2 z=x^{2}+y^{2}$ & 64 & 87 \\
\hline $1.3 x y=3$ & 69 & 89 \\
\hline $1.4 y=x^{3}$ & 72 & 95 \\
\hline $1.5 x^{2}+y^{2}=3$ & 74 & 94 \\
\hline
\end{tabular}

In comparing results in Tables 1 and 2, there was significant increase in the scores for both groups. This means that students gained from both approaches. However, it appears that the experimental group experienced greater gains. The findings aligned with the claim by some researchers [2, 4, 30, 54] that dynamic visual tools (such as: CAS, MATHEMATICA, and MATLAB) could enhance mathematics achievement. From the statistical results obtained from scrutinising rural-based pre-service teachers' conceptual, procedural, and factual knowledge through the solutions and comments they provided, we have reason to support the claims by those authors $[2,4,30$, 54]. 
Question 2.1a: How do rural-based pre-service teachers apply their spatialvisualisation skills in problem solving? It was found that even though the participants had encountered some fundamentals of vectors in high school, they had difficulty in handling fundamental vector operations (such as sketching and describing vector diagrams and addition and subtraction of vectors (refer to Figure 6) in college. An implication from previous work [22] is that, even though vector tasks require high spatial-visualisation skills. This may further explain why less attention is paid to graphical functions. The theory further elaborated that, while analysis starts with coordinates of an object (visualization), as it continues richer visuals are formed which help in problem-solving situations. Conversely, lack of coordination between visual and analysis results hinders problem-solving situations.

Question 3: How do rural-based pre-service teachers apply the spatial-visualisation skills in solving integral calculus? From excerpts from the work of participant EG036, it can be deduced that some students are more comfortable performing routine task such as working with mathematics equations but feel reluctant or unable to work in the context of function graphs. They struggle in switching between registers (e.g., geometric register to algebraic register) perhaps, as hypothesised [53], because this may be too cognitively demanding. This connects with previous [24, 55] assertions that students are reluctant to work in geometric registers. Furthermore, it seems that the participants in this study who were able to draw a correct sketch (3D shape of cube) to represent the problem also accurately wrote the integral equation and performed the integration procedure (refer to Figure 10). However, the respective difficulty observed when this process was reversed provides support to researchers [60] (2003) claim that students' difficulties in problem-solving is born from their inability to meaningfully visualise mathematical concepts and manipulate and interpret geometrical shapes. Hence, all the study participants who accurately used a sketch to represent the question tended to present the correct solution. While we, therefore, conclude that the dynamic visual environment, MATLAB, can significantly enhance conceptual understanding, procedural skills, and factual reasoning, the exact mechanism explaining this association between visual and analysis was not accounted for in the scope of this research study.

Conclusively, the evidence revealed strong nexus between learning and MATLAB in current scenario. Thus, there is the need to augment learning through MATLAB being critical for the knowledge development.

\section{$7 \quad$ Limitations}

The limitations of this study are numerous. Among others, we cannot guarantee that other populations - even from other high-poverty, rural universities - would produce similar results to this study. We are currently unwilling to generalize beyond our research population. However, we are glad to see such positive results from the experimental group with limited involvement with MATLAB.

This study did not analyse the data in respect to individual student past mathematical performance. For instance, while we see that generally the group using MATLAB 
gained more in SV skills and mathematical understanding, we do not know if resulting changes were greater for some sub populations of these students than others (e.g., lower versus higher performing students).

We did not survey participant familiarity with technology prior to this study. We assumed that this was relatively homogeneous throughout the entire participant population, since, for a couple years prior to this study: (A) they had all attended the same university, (B) under the same pre-service teacher program of study, and (C) had taken a very similar path of courses requiring similar uses of technology. However, technology ability may have been more heterogeneous than assumed.

Additionally, regarding replicability, we cannot guarantee that other instructors would have similar results. We recognize that there are numerous factors at play in the instructor/student relationship which play roles in student experiences and learning.

Last, there were many conjoined variables which could not be disaggregated. For instance, it is possible for "high-poverty" and "rural" to be disjoint variables with each having different effects on student use of technology, SV development, and mathematical development. This is left for future research.

\section{Conclusion}

The evidence establishes strong nexus between learning and MATLAB as a new technology. This is because, from the above, the empirical evidences gathered from the pre-test, post-test and content analysis revealed that most of the rural-based preservice teachers have challenges ranging from their inabilities to: visualise and sketch space figures, translate between graphic and algebraic representation in $3 \mathrm{D}$, sketch and describe vector plots, translate vector word problems into algebraic equation, perform vector operations, and set up double and triple integral of vector equations. From the statistical evidence gathered, the use of MATLAB as a dynamic visual tool supporting and building spatial-visualisation skills can enhance problem solving and achievement in the context of vector calculus. This substantiates the interrelationships between dynamic visual tools, problem-solving skills, and achievement. Hence, we can conclude that the use dynamic computer technology can be successfully and productively employed in rural-based universities in enhancing mathematics problemsolving skills, achievement, and spatial-visualisation skills.

\section{Reference}

[1] Altakhaineh, A. R. M., \& Al-Jallad, M. Z. (2018). The Use of Twitter and Facebook in Teaching Mechanics of Writing to Arabic-Speaking EFL Learners. International Journal of Emerging Technologies in Learning, 13(09), 4-14. https://doi.org/10.3991/ijet.v13i09.8457

[2] Arcavi, A. (2003). The role of visual representations in the learning of mathematics. Educational Studies in Mathematics, 52(3): 215-241.

[3] Arici, S., \& Aslan-Tutak, F. (2015). The effect of origami-based instruction on spatial visualization, geometry achievement, and geometric reasoning. International Journal of Sci- 
ence and Mathematics Education, 13(1): 179-200. https://doi.org/10.1007/s10763-013$\underline{9487-8}$

[4] Bakó, M. (2003). February. Different projecting methods in teaching spatial geometry. In Proceedings of the Third Conference of the European society for Research in Mathematics Education.

[5] Baltaci, S., \& Yildiz, A. (2015). GeoGebra 3D from the perspectives of elementary preservice mathematics teachers who are familiar with several software programs. Online Submission, 10(1): 12-17.

[6] Brake, M. L. (2009). Matlab as a tool to increase the math self-confidence and the math ability of first-year engineering technology students. The Scholarship of Teaching and Learning at EMU, 1(1): 5.

[7] Casey, B. M., Pezaris, E., Fineman, B., Pollock, A., Demers, L., \& Dearing, E. (2015). A longitudinal analysis of early spatial skills compared to arithmetic and verbal skills as predictors of fifth-grade girls' math reasoning. Learning and Individual Differences, 40, 90100. https://doi.org/10.1016/j.lindif.2015.03.028

[8] Chaamwe, N. (2010). Integrating ICTS in the teaching and learning of mathematics: An overview. 2nd International Workshop on Education Technology and Computer Science, https://doi.org/10.1109/etcs.2010.163.

[9] Chen, C. H., \& Su, C. C. C. (2013). An integrated design flow in developing an augmented reality game for enhancing children chinese learning experience. International Journal of Digital Content Technology and its Applications, 7(4), 907. https://doi.org/10.4156/jdcta. vol7.issue4.109

[10] Cheng, Y. L., \& Mix, K. S. (2014). Spatial training improves children's mathematics ability. Journal of Cognition and Development, 15(1), 2-11.

[11] Cumbee, C. M. V. (2017). Elementary teachers' use of technology for teaching and parent communication in low socio-economic classrooms: A case study. Northcentral University, ProQuest Dissertations Publishing, 2017. 10263560.

[12] Daud, W. A. A. W., Ghani, M. T., \& Zaki, A. (2018). MOOC at Universiti Malaysia Kelantan: Need Analysis Study for the Development of Arabic Language Online Course. International Journal of Arts Humanities and Social Sciences, 1, 1-10.

[13] Delice, A., \& Ergene, Ö. (2015). Investigation of drawings and rotation skills in integral volume problems solving process within communities of practices. Journal of Theory and Practice in Education, 11(4), 1288-1309.

[14] Denis, M. (1991). Imagery and thinking. In C. Cornoldi \& M. McDaniel (Eds.), Imagery and cognition (pp. 103-131). New York, NY: Springer. https://doi.org/10.1007/978-14684-6407-8 4

[15] Doughty, L., McLoughlin, E., \& Van Kampen, P. (2014). What integration cues, and what cues integration in intermediate electromagnetism. American Journal of Physics, 82(11), 1093-1103. https://doi.org/10.1119/1.4892613

[16] Dray, T., \& Manogue, C. A. (2003). Using differentials to bridge the vector calculus gap. The College Mathematics Journal, 34(4), 283. https://doi.org/10.2307/3595765

[17] Duval, R. (1999). Representation, vision and visualization: Cognitive functions in mathematical thinking. Basic issues for learning. Proceedings of the Annual Meeting of the North American Chapter of the International Group for the Psychology of Mathematics Education, Cu-ernavaca, Morelos, México.

[18] Duval, R. (2006). A cognitive analysis of problems of comprehension in a learning of mathematics. Educational Studies in Mathematics, 61, 103-131.

[19] Ertekin, E. (2014). Is Cabri 3D Effective for the Teaching of Special Planes in Analytic Geometry. International Journal of Educational Studies in Mathematics, 1(1), 27-36. https://doi.org/10.17278/ijesim.2014.01.003

[20] Farmer, G., Verdine, B. N., Lucca, K., Davies, T., Dempsey, R., Hirsh-Pasek, K., \& Golinkoff, R. M. (2013). Putting the pieces together: Spatial skills at age 3 predict to spatial 
and math performance at age 5. Poster presented at the 2013 Meeting of The Society for Research in Child Development Conference, Seattle, WA.

[21] Ferrer, F. P. (2016). Investigating students' learning difficulties in integral calculus. People: International Journal of Social Sciences, 2(1).

[22] Fleisch, D. A. (2011). A student's guide to vectors and tensors. Cambridge, UK: Cambridge University Press.

[23] Galbis, A., \& Maestre, M. (2012). Vector analysis versus vector calculus. Springer Science \& Business Media.

[24] Gilligan, K. A., Flouri, E., \& Farran, E. K. (2017). The contribution of spatial ability to mathematics achievement in middle childhood. Journal of Experimental Child Psychology, 163, 107-125. https://doi.org/10.1016/j.jecp.2017.04.016

[25] Gire, E., \& Price, E. (2012). February. Graphical representations of vector functions in upper-division E\&M. In AIP Conference Proceedings 1413(1), 27-30.

[26] Guay, R. B. (1976). Purdue spatial visualization test. West Lafayette, Indiana: Purdue Research Foundation.

[27] Ho, S. Y., \& Lowrie, T. (2014). The model method: Students' performance and its effectiveness. The Journal of Mathematical Behavior, 35, 87-100.

[28] Höffler, T. N. (2010). Spatial ability: Its influence on learning with visualizations - a metaanalytic review. Educational Psychology Review, 22(3), 245-269. https://doi.org/10.1007/ s10648-010-9126-7

[29] Höffler, T. N., \& Leutner, D. (2011). The role of spatial ability in learning from instructional animations - evidence for an ability-as-compensator-hypothesis. Computers in Human Behavior, 27, 209- 216. https://doi.org/10.1016/j.chb.2010.07.042

[30] Jansen, P., Schmelter, A., Quaiser-Pohl, C., Neuburger, S., \& Heil, M. (2013). Mental rotation performance in primary school age children: Are there gender differences in nometric tests? Cognitive Development, 28(1), 51-62. https://doi.org/10.1016/j.cogdev.20 12.08 .005

[31] Kazimovich, Z. M., \& Guvercin, S. (201)2. Applications of Symbolic computation in MATLAB. International Journal of Computer Applications, 41(8).

[32] Kebritchi, M., Hirumi, A., \& Bai, H. (2010). The effects of modern mathematics computer games on mathematics achievement and class motivation. Computers \& education, 55(2), 427-443. https://doi.org/10.1016/j.compedu.2010.02.007

[33] Kohl, P. B., \& Finkelstein, N. D. (2005). Student representational competence and selfassessment when solving physics problems. Physical Review Special Topics-Physics Education Research, 1(1), 010104. https://doi.org/10.1103/physrevstper.1.010104

[34] Kösa, T. (2016). The effect of using dynamic mathematics software: Cross section and visualization. International Journal for Technology in Mathematics Education, 23(4), 121128.

[35] Mahir, N. (2009). Conceptual and procedural performance of undergraduate students in integration. International Journal of Mathematical Education in Science and Technology, 40(2), 201-211. https://doi.org/10.1080/00207390802213591

[36] Majid, M. A., Huneiti, Z. A., Balachandran, W., \& Balarabe, Y. 2013). MATLAB as a teaching and learning tool for mathematics: A literature review. International Journal of Arts and Sciences, 6(3), 23-44.

[37] McLeay, H. (2006). Imagery, spatial ability and problem solving. Mathematics Teaching Incorporating Micromath, 195, 36-38.

[38] Newcombe, N. S., \& Shipley, T. F. (2015). Thinking about spatial thinking: New typology, new assessments. In G. S. Gero (Ed.), Studying visual and spatial reasoning for design creativity (pp. 179-192). Dordrecht, Netherlands: Springer. https://doi.org/10.1007/978-94017-9297-4_10

[39] Nguyen, D. H., \& Rebello, N. S. (2011). Students' difficulties with multiple representations in introductory mechanics. Online Submission, 8(5), 559-569. 
[40] Nguyen, D.H., Gire, E., \& Rebello, N. S. (2010). Facilitating Students' Problem Solving Across Multiple Representations in Introductory Mechanics. Invited, Proceedings of the 2010 Physics Education Research Conference, AIP Publications, July 21 - 22, 2010, Portland, or. https://doi.org/10.1063/1.3515244

[41] Ogunkunle, R. A., Charles-Ogan, G., \& Harcourt, P. (2013). Dependence on calculators for acquisition of basic skills in junior secondary school Mathematics. Journal of Research in National Development (JORIND), 11 (1), 228, 232.

[42] Park, J., \& Brannon, E. M. (2013). Training the approximate number system improves math proficiency. Psychological Science, 24(10), 2013-2019. https://doi.org/10.1177/09 56797613482944

[43] Phillips, L. M., Norris, S. P., \& Macnab, J. S. (2010). The concept of visualization. In Visualization in mathematics, reading and science education (pp. 19-34). Dordrecht, Netherlands: Springer.

[44] Piaget, J., \& Inhelder, B. (1966). L'image mentale chez l'enfant. [The mental image in the child]. Presses Universitaires de France.

[45] Puhak, R. I., Hall, S., \& Street, W. (2011). Teaching Applied Calculus utilizing MATLAB'. In Proceedings of the Twenty-third Annual International Conference on Technology in Collegiate Mathematics.

[46] Rebello, N. S., Engelhardt, P. V., \& Singh, C. (2012). Physics Education Research Conference. In American Institute of Physics Conference Series, 1413.

[47] Robertson, R. L. (2013). Early vector calculus: A path through multivariable calculus. Primus, 23(2), 133-140. https://doi.org/10.1080/10511970.2012.702709

[48] Rosengrant, D., Etkina, E., \& Van Heuvelen, A. (2007). An overview of recent research on multiple representations. In AIP Conference Proceedings, 883(1), 149-152). AIP. https:// doi.org/10.1063/1.2508714

[49] Shepard, R. N., \& Feng, C. (1972). A chronometric study of mental paper folding. Cognitive Psychology, 3(2), 228-243. https://doi.org/10.1016/0010-0285(72)90005-9

[50] Shepard, R. N., \& Metzler, J. (1971). Mental rotation of three-dimensional objects. Science, 171(3972), 701-703. https://doi.org/10.1126/science.171.3972.701

[51] Shum, J., Hermes, D., Foster, B. L., Dastjerdi, M., Rangarajan, V., Winawer, J. \& Parvizi, J. (2013). A brain area for visual numerals. Journal of Neuroscience, 33(16), 6709-6715. https://doi.org/10.1523/jneurosci.4558-12.2013

[52] Šipuš, Ž. M., \& Cizmešija, A. (2012). Spatial ability of students of mathematics education in Croatia evaluated by the Mental Cutting Test. Ann. Math. Inform, 40, 203-216.

[53] Stieff, M., \& Uttal, D. (2015). How much can spatial training improve STEM achievement? Educational Psychology Review, 27(4), 607-615. https://doi.org/10.1007/s1 0648-015-9304-8

[54] Strong, S., \& Smith, R. (2001). Spatial visualization: Fundamentals and trends in engineering graphics. Journal of Industrial Technology, 18(1), 1-6.

[55] Sweller, J. (1999). Instructional design in technical areas. Melbourne: ACER Press.

[56] Tokpah, C. L. (2008). The effects of computer algebra systems on students' achievement in mathematics (Doctoral dissertation, Kent State University).

[57] Trigueros, M. (2004). October. Understanding the meaning and representation of straightline solutions of systems of differential equations. In Proceedings of the twenty-sixth annual meeting of the North American Chapter of the International Group for the Psychology of Mathematics Education (pp. 127-134)

[58] Ursache, A., \& Noble, K. G. (2016). Neurocognitive development in socioeconomic context: Multiple mechanisms and implications for measuring socioeconomic status. Psychophysiology, 53(1), 71-82. https://doi.org/10.1111/psyp.12547

[59] Uttal, D. H., Meadow, N. G., Tipton, E., Hand, L. L., Alden, A. R., Warren, C., \& Newcombe, N. S. (2013). The malleability of spatial skills: A meta-analysis of training studies. Psychological Bulletin, 139(2), 352. https://doi.org/10.1037/a0028446 
[60] Van Garderen, D., \& Montague, M. (2003). Visual-spatial representation, mathematical problem solving, and students of varying abilities. Learning Disabilities Research \& Practice, 18(4), 246-254. https://doi.org/10.1111/1540-5826.00079

[61] Verdine, B. N., Golinkoff, R. M., Hirsh-Pasek, K., Newcombe, N. S., Filipowicz, A. T., \& Chang, A. (2014). Deconstructing building blocks: Preschoolers' spatial assembly performance relates to early mathematical skills. Child Development, 85(3), 1062-1076. https://doi.org/10.1111/cdev.12165

[62] Wade, B. S., Joshi, S. H., Gutman, B. A., \& Thompson, P. M. (2017). Machine learning on high dimensional shape data from subcortical brain surfaces: A comparison of feature selection and classification methods. Pattern Recognition, 63, 731-739. https://doi. org/10.1016/j.patcog.2016.09.034

[63] Wagner, J. F., Manogue, C. A., \& Thompson, J. R. (2012). Representation issues: Using mathematics in upper-division physics. In AIP Conference Proceedings, 1413(1), 89-92.

[64] Wolfgang C. H., Stannard L. L., Jones I. (2001). Block play performance among preschoolers as a predictor of later school achievement in mathematics. Journal of Research in Childhood Education, 15, 173-180. https://doi.org/10.1080/02568540109594958

[65] Zazkis, R., Dubinsky, E., \& Dautermann, J. (1996). Coordinating visual and analytic strategies: A study of students' understanding of the group D 4. Journal for Research in Mathematics Education, 435-457. https://doi.org/10.2307/749876

[66] Zhang, X., Koponen, T., Räsänen, P., Aunola, K., Lerkkanen, M. K., \& Nurmi, J. E. (2014). Linguistic and spatial skills predict early arithmetic development via counting sequence knowledge. Child Development, 85(3), 1091-1107. https://doi.org/10.1111/cdev. $\underline{12173}$

\section{Authors}

Godfred Amevor, current researcher, has his research interest in adaptive technologies and visualisation. He is currently pursuing his $\mathrm{Ph}$. D in cognitive enhancement in adaptive technologies with University of Zululand, South Africa.

Anass Bayaga, editorial board member of international journal of mathematics teaching and learning (IJMTL), is STEM cognition professor at Nelson Mandela University. Previously a visiting researcher at Umea University- Sweden, Appalachian State University, USA, Anass was also a Fulbright researcher at the George Washington University, where he previously researched cognitive enhancement via adaptive technologies.

Michael J. Bossé, chief-editor of international journal of mathematics teaching and learning (IJMTL), is a distinguished professor of Mathematics Education and MELT Program Director at the Department of Mathematical Sciences, Appalachian State University, USA. Michael has extensive research interest in mathematics cognition with continuous collaborations in Africa. Michael has published extensive in the USA and African context in the field of mathematics cognition and.

Article submitted 2020-10-17. Resubmitted 2020-12-07. Final acceptance 2020-12-09. Final version published as submitted by the authors. 